\title{
Effect of a Comprehensive Health Care Program by Korean Medicine Doctors on Medical Care Utilization for Common Infectious Diseases in Child-Care Centers
}

\author{
Minjung Park, ${ }^{1}$ Jimin Park, ${ }^{2}$ and Soonman Kwon ${ }^{3}$ \\ ${ }^{1}$ Graduate School of Public Health, Seoul National University, Sillim-dong, Kwanak-gu, Seoul 151-742, Republic of Korea \\ ${ }^{2}$ Division of Traditional Korean Medicine Industry, Ministry of Health and Welfare, Doum 4-ro, Sejong-si 339-012, Republic of Korea \\ ${ }^{3}$ Graduate School of Public Health, Seoul National University, Sillim-dong, Kwanak-gu, Seoul 151-742, Republic of Korea
}

Correspondence should be addressed to Soonman Kwon; kwons@snu.ac.kr

Received 14 May 2014; Revised 28 July 2014; Accepted 28 July 2014; Published 11 September 2014

Academic Editor: Vassya Bankova

Copyright (C) 2014 Minjung Park et al. This is an open access article distributed under the Creative Commons Attribution License, which permits unrestricted use, distribution, and reproduction in any medium, provided the original work is properly cited.

As the role of traditional medicine in community health improvement increases, a comprehensive health care program for infectious diseases management in child-care centers by Korean medicine doctors was developed. The purpose of this study is to evaluate the effects of the program intervention on infection-related medical care utilization among children. The study used a quasiexperimental design with nonequivalent control group, comparing pre- and post-intervention data of the same children. The program implemented interventions in terms of management, education, and medical examination for the teachers, parents, and children in 12-week period. The frequency of utilization, cost, and prescription days of drugs and antibiotics due to infectious diseases prior to the intervention were compared with those during the 3-month intervention, using health insurance claim data. A panel analysis was also conducted to support the findings. A significant reduction (12\%) in infection-related visit days of hospitals was observed with the intervention (incident rate ratio $=0.88, P=0.01$ ). And medical cost, drug prescription days, and antibiotics prescription days were decreased, although not statistically significant. A further cost-effectiveness analysis in terms of social perspectives, considering the opportunity costs for guardians to take children to medical institutions, would be needed.

\section{Introduction}

The number of infants supported in child-care centers has been increasing remarkably, due to changes in major social and demographic trends, altering the structure and function of families in Korea. Parents as well as health care professionals are concerned about the health and safety of children who spend all or part of their days in child-care settings. These concerns include the high incidence of infectious diseases transmission among child-care populations [1]. In fact, it was reported that children who attend child-care centers have higher prevalence of infectious diseases [2-7]. Conventional health intervention program to reduce these incidences of infectious diseases in child-care center seems insufficient.

World Health Organization (WHO) emphasized that traditional medicine can be a useful approach to resolve community health problems [8] and recommended the use of traditional medicine in primary health care at policy level [9]. In Korea, it is reported that $77.5 \%$ of Korean people have used Korean traditional medicine. Furthermore, $94.3 \%$ of Korean traditional medical care is provided in ambulatory settings such as in primary health care [10]. Such results show the important role of Korean medicine in both protecting and restoring health, which are appropriate for the enhancement of primary health.

Although the public health program of Korean medicine through public health care centers was implemented since 2005 [11], comprehensive health care program in child-care centers has not been yet implemented. This has motivated us to develop a comprehensive health care program for infectious diseases management in child-care centers by Korean medicine doctors. In this study, we conducted the evaluation of the program effect on medical care utilization to prevent infectious diseases and to promote health, using data from 
Korea Health Insurance Review and Assessment service (HIRA), following prior study using survey data from parents of children and teachers [12].

\section{Materials and Methods}

2.1. Study Design and Subjects. The study adopts a quasiexperimental design with nonequivalent control groups and measures, taking pre- and post-intervention evaluation of the same children. This design is considered to be useful for community-based interventions, in which randomization is not possible. First, six day-care centers located in Seoul and Kyung-gi province volunteered for this program. Researchers visited there and explained the purpose and contents of the program and then collected data with the permission of the parents of children. To control Hawthorn effect, participants were not informed of the program evaluation criteria. Second, other six day-care centers, which shared similar characteristics in size, location and ownership, have been selected as control groups. To control for the contamination of control group (John Henry effect), the purpose of the research is explained to examine the current state of infectious diseases prevalence. Third, six doctors of Korean medicine were provided with common education about the program and assigned to each of the experimental group.

After 3 months of implementation, we analyzed the claims data of infants to determine the changes in medical care utilization, such as frequency, cost and prescription days of drug and antibiotics between the treated and the untreated. Finally, 227 out of 251 in the treated group and 92 out of 321 in the untreated group were included by informed consent.

2.2. Intervention Program. The program provides management, education, and medical examination support for the teachers, parents, and children for 12 weeks (from August 2012 to October 2012). The program was implemented by Korean medicine doctors using preventive concepts of Korean medicine, Yangsaeng (養生) (Yangsaeng (養生) is a traditional health care regimen for the promotion of health and prevention of illness by means of specific principles and methods, whose purpose was to improve longevity and healthy life [13]) and Chimibyeong (治未病) (Chimibyeong (治未病) is a theory to prevent disease from occurring, worsening, being delivered, and so on; in many books, the word Chimibyeong was used as a term of preventing a disease or used as a word meaning treating a disease in the early stage [14]), in cooperation with the parents, children, and teachers. Six Korean medicine doctors were recruited through an online notification in the homepage of "The Association of Korean Medicine," who were restricted to a pediatrician of Korean medicine, a Korean medicine doctor in Korean medical clinic for pediatric specialty, or Korean medicine doctors with over-5-year clinical experience.

The primary goal of the program is to prevent infectious diseases and promote health in child-care centers. The program was supported with inputs from 1 public health professor, 1 professor of pediatrics in the Korean Medicine Hospital of Kyunghee University, and 1 pediatrician for Korean medicine. Specific details of the program are illustrated and summarized in Figure 1.

2.2.1. Management. The management includes the control of infectious diseases in child-care centers. Before intervention, child-care centers were provided with a box of household medicines, including Korean medicines, which treat early stage of common infectious diseases and prevent the progress of diseases. The Korean medicine doctor visits child-care centers in one-on-one setting, educating teachers about the use of household medicines, provided to manage symptoms according to the "Yangsaeng." The purpose of this visit and education was to improve the knowledge of caregivers and prevent possible contraction of disease through appropriate action from teachers.

To promote a preventive attitude of teachers on infection, teachers were advised to monitor and record the occurrence of symptoms of infectious diseases and children's attendance. When needed, they were guided to use household medicines under the management of doctors with parent's approval. The Korean medicine doctor visits child-care center monthly and follows up observations on children with symptoms by checking the records taken by teachers and through talks with the teachers. In addition, during their visit to the child-care center, the Korean medicine doctors guided the teachers in managing symptoms using household medicines and conducted examination and consultation of children who have infectious symptoms. During the study, the Korean medicine doctor kept in touch with child-care centers through phone and emails, providing consultations and support in emergency cases and in guiding the management of early signs of disease and its symptoms.

2.2.2. Education. Education about a summary of frequent infectious diseases and preventive behavior and management in Korean medicine was provided to parents and teachers once for 80 minutes by Korean medicine doctors.

2.2.3. Medical Examination. The survey was conducted to examine the children's functional and physical symptoms and health status through parent's interviews. The survey consists of systemic questions about the general development of children under the Five Organs theory in Korean medicine. The Korean medicine doctor checks the survey, sorts children who needed consultation and management, and examines them personally including children's health management guidance such as Yangsaeng for their parents and volunteers.

2.3. Data and Statistical Analysis. Claim data of 319 infants in agreement was retrieved from Korea "Health Insurance Review and Assessment Service." Medical care utilization, such as frequency of visit, costs, and prescription days of drugs and antibiotics due to infectious diseases prior to the intervention (from May 1, 2012, to July 31, 2012), was compared with those within the 3 months of intervention (from August 1, 2012, to October 31, 2012). We have also carried 


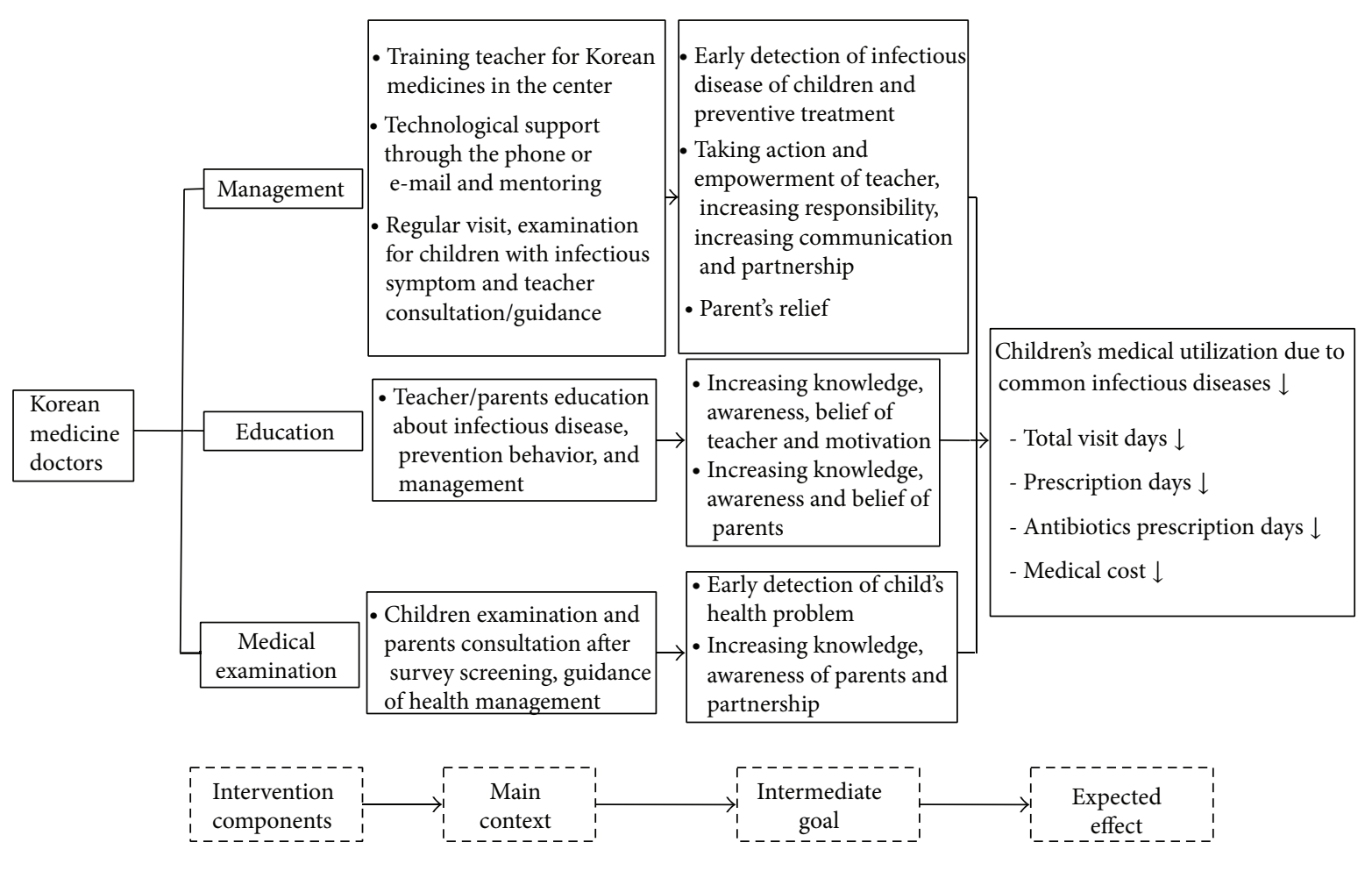

FIGURE 1: Design of the comprehensive health care program for child-care centers.

out the survey before intervention targeting the full sample (572 infant) to find out the basic features of participants and to compare them with those who do not participate in the study.

We conducted a panel analysis to estimate the effect of the comprehensive health care program on medical care utilization of children, specifically on common infectious diseases. In the case of panel data, the change in medical care utilization by the same individual is traced, so that more exact effect of intervention can be measured. In other words, it is possible to control for individual-specific, time-invariant, and unobserved heterogeneity, which may be correlated with other explanatory variables [15]. Although there are potentially many factors affecting the frequency of infections even when the groups are assessed during the same temporal period, panel model seems to control some features that are hard to observe but can be related to medical care utilization, such as unclean environment, vulnerabilities to infection, related past history of illness that parents may not remember, and inherited traits.

This research also adopted a random effect model, since the study period is too short ( 3 months) to produce sufficient within-unit variance and has data limitations as it only has two waves. Data was analyzed using STATA ver. 11.

2.4. Research Ethics. This research was approved by the Institutional Review Board of the Graduate School of Public Health, Seoul National University (IRB number 19-2012-0604).

\section{Results}

\subsection{Group Equivalence}

3.1.1. Between the Treated and the Untreated. In the case of the community-based health promotion program, it is difficult to conduct randomization. Since this program participation was voluntary, we matched the case group (one to one) with the control group with similar characteristics in size, location, ownership, and so forth (Table 1).

3.1.2. Between Consenters and Nonconsenters. Since the claim data contain information about individual health and behavior, some participants are concerned about making their medical care utilization information public. Some of the parents did not agree to use information on their children's medical care utilization, and this was more distinct in the untreated group where there was little room for confidence formed between the parents and the researchers. If there is selection bias due to the consent of information, the program effect would be overestimated or underestimated; therefore the first step in the program was to assess homogeneity between consenters and nonconsenters. Before intervention, we carried out survey targeting the full sample (572 infant) to find out the basic characteristics and usual symptoms related to infection and compared the consenters with nonconsenters. This procedure will determine the existence of any systemic difference between consenters and nonconsenters. 
TABLE 1: The characteristics of child-care centers.

\begin{tabular}{|c|c|c|c|c|c|c|c|c|c|c|c|c|}
\hline \multirow{2}{*}{$\begin{array}{l}\text { Group } \\
\text { Area }\end{array}$} & \multicolumn{6}{|c|}{ Treated } & \multicolumn{6}{|c|}{ Untreated } \\
\hline & S & $\mathrm{S}$ & $\mathrm{S}$ & G & G & G & $\mathrm{S}$ & $\mathrm{S}$ & $\mathrm{S}$ & G & G & G \\
\hline Types & $\mathrm{P}$ & PS & PS & $\mathrm{Pt}$ & $\mathrm{P}$ & $\mathrm{K}$ & $\mathrm{P}$ & PS & PS & $\mathrm{Pt}$ & $\mathrm{P}$ & $\mathrm{K}$ \\
\hline Size (number of children) & 86 & 39 & 31 & 104 & 91 & 133 & 80 & 51 & 39 & 125 & 70 & 160 \\
\hline Number of teachers & 12 & 5 & 5 & 9 & 7 & 9 & 15 & 10 & 7 & 11 & 6 & 8 \\
\hline Visiting health care profession & $\mathrm{N}$ & $\mathrm{N}$ & $\mathrm{N}$ & $\mathrm{N}$ & $\mathrm{N}$ & $\mathrm{N}$ & $\mathrm{N}$ & $\mathrm{N}$ & $\mathrm{N}$ & $\mathrm{N}$ & $\mathrm{N}$ & $\mathrm{N}$ \\
\hline Health record & $\mathrm{Y}$ & $\mathrm{Y}$ & $\mathrm{Y}$ & $\mathrm{Y}$ & $\mathrm{Y}$ & $\mathrm{Y}$ & $\mathrm{Y}$ & $\mathrm{Y}$ & $\mathrm{Y}$ & $\mathrm{Y}$ & $\mathrm{Y}$ & $\mathrm{Y}$ \\
\hline
\end{tabular}

S: Seoul, G: Gyeonggi-do.

P: public; PS: private (Seoul-type); Pt: private; K: kindergarten.

N: no; Y: yes.

TABLE 2: Characteristics of infants.

\begin{tabular}{|c|c|c|c|c|}
\hline & & $\begin{array}{l}\text { Consenters (\%) } \\
\quad(n=319)\end{array}$ & $\begin{array}{c}\text { Nonconsenters }(\%) \\
(n=253)\end{array}$ & $P$ \\
\hline \multicolumn{2}{|c|}{ Age } & $5.52 \pm 1.20$ & $5.67 \pm 1.28$ & 0.14 \\
\hline \multirow{2}{*}{ Sex } & Male & $181(56.74)$ & $116(48.74)$ & \multirow{2}{*}{0.06} \\
\hline & Female & $138(43.36)$ & $122(51.26)$ & \\
\hline \multirow{2}{*}{ Duration } & Under $1 \mathrm{yr}$ & $81(25.47)$ & $48(19.05)$ & \multirow{2}{*}{0.07} \\
\hline & Over $1 \mathrm{yr}$ & $237(74.53)$ & $204(80.95)$ & \\
\hline \multirow{2}{*}{ Past history } & Yes & $168(57.14)$ & $143(57.66)$ & \multirow{2}{*}{0.90} \\
\hline & No & $126(42.86)$ & $105(42.34)$ & \\
\hline \multicolumn{2}{|c|}{ Number of siblings } & $1.97 \pm 0.64$ & $2.05 \pm 0.68$ & 0.17 \\
\hline \multirow{2}{*}{ Main carer } & Mother & $271(89.44)$ & $216(86.06)$ & \multirow{2}{*}{0.22} \\
\hline & etc. & $32(10.56)$ & $35(13.94)$ & \\
\hline \multirow{2}{*}{ Health insurance coverage } & Medicaid & $9(3.14)$ & $20(8.37)$ & \multirow{2}{*}{$0.01^{*}$} \\
\hline & National Health Ins. & $278(96.86)$ & $219(91.63)$ & \\
\hline \multirow{2}{*}{ Household income } & Under 4,000 & $162(54.92)$ & $136(59.13)$ & \multirow{2}{*}{0.33} \\
\hline & Over 4,000 & $133(45.08)$ & $94(40.87)$ & \\
\hline \multirow{2}{*}{ Mom's education } & Below high school & $53(18.15)$ & $38(15.70)$ & \multirow{2}{*}{0.45} \\
\hline & Over college & $239(81.85)$ & $204(84.30)$ & \\
\hline \multirow{2}{*}{ Mom's job } & Working mom & $158(53.02)$ & $135(55.79)$ & \multirow{2}{*}{0.52} \\
\hline & Household & $140(46.98)$ & $107(44.21)$ & \\
\hline
\end{tabular}

${ }^{*} P<0.05$.

In the presurvey, no significant differences between consenters and nonconsenters were detected, except for health insurance coverage (Table 2). National health insurance subscribers are $96.86 \%$ in consenters and $91.63 \%$ in nonconsenters. Medical care utilization pattern may show differences between national health insurance subscribers and medical aid recipients, but this is adjusted in the panel regression analysis.

In infection-related symptoms, most of them occurred less frequently in consenters. Only nasal discharge was reported more frequently in consenters (Table 3 ).

3.2. Screening of Infection-Related Medical Care Utilization. The medical care utilization data for frequent infectious diseases was screened through a consultation with 1 pediatrician of western medicine and 1 pediatrician of Korean medicine, to select appropriate medical care utilization data for the purpose of this study. In the total of 4,379 cases,
764 cases were excluded such as dental clinic utilization, resulting in 3,615 cases for the analysis. The criteria on disease classification are shown in Table $4.1,866$ cases in 3,615 cases have occurred in the 3 months prior to the intervention, and 1,749 cases have occurred during the intervention which lasted for 3 months.

3.3. Basic Characteristics of Participants. Table 5 summarizes the initial demographic characteristics of 319 informants who are divided into treated and untreated groups. Before evaluating the impact of intervention, it was necessary to show that two groups were similar on variables that could be associated with outcomes. As shown in Table 4, no significant differences were detected in dependent variables of two groups. Also, very few differences between two groups were found in independent variables. Higher extent of mother as a main carer of the infant and lower level of household income were observed in the treated group. 
TABLE 3: Infection-related symptoms during 2 weeks, shortly before the intervention.

\begin{tabular}{|c|c|c|c|c|}
\hline \multirow[b]{2}{*}{ Characteristics or variables } & \multicolumn{4}{|c|}{$n=572$} \\
\hline & $\begin{array}{c}\text { Consenters } \\
(n=319)\end{array}$ & $\begin{array}{l}\text { Nonconsenters } \\
\quad(n=253)\end{array}$ & $\chi^{2}$ & $P$ \\
\hline \multicolumn{5}{|l|}{ Fever } \\
\hline Yes & $14.85 \%$ & $14.29 \%$ & \multirow{2}{*}{0.04} & \multirow{2}{*}{0.85} \\
\hline No & $85.15 \%$ & $85.71 \%$ & & \\
\hline \multicolumn{5}{|l|}{ Cough } \\
\hline Yes & $28.38 \%$ & $29.37 \%$ & \multirow{2}{*}{0.93} & \multirow{2}{*}{0.63} \\
\hline No & $71.62 \%$ & $70.63 \%$ & & \\
\hline \multicolumn{5}{|l|}{ Sneeze } \\
\hline Yes & $14.19 \%$ & $15.14 \%$ & \multirow{2}{*}{0.10} & \multirow{2}{*}{0.75} \\
\hline No & $85.81 \%$ & $84.86 \%$ & & \\
\hline \multicolumn{5}{|l|}{ Nasal discharge } \\
\hline Yes & $40.59 \%$ & $30.95 \%$ & \multirow{2}{*}{5.54} & \multirow{2}{*}{$0.02^{*}$} \\
\hline No & $59.41 \%$ & $69.05 \%$ & & \\
\hline \multicolumn{5}{|l|}{ Nasal congestion } \\
\hline Yes & $20.79 \%$ & $20.63 \%$ & \multirow{2}{*}{0.00} & \multirow{2}{*}{0.96} \\
\hline No & $79.21 \%$ & $79.37 \%$ & & \\
\hline \multicolumn{5}{|l|}{ Epistaxis } \\
\hline Yes & $11.55 \%$ & $10.71 \%$ & \multirow{2}{*}{0.10} & \multirow{2}{*}{0.76} \\
\hline No & $88.45 \%$ & $89.29 \%$ & & \\
\hline \multicolumn{5}{|l|}{ Abd. pain } \\
\hline Yes & $15.51 \%$ & $13.89 \%$ & \multirow{2}{*}{0.29} & \multirow{2}{*}{0.59} \\
\hline No & $84.49 \%$ & $86.11 \%$ & & \\
\hline Diarrhea & & & & \\
\hline Yes & $7.59 \%$ & $5.56 \%$ & 099 & 034 \\
\hline No & $92.41 \%$ & $94.44 \%$ & 0.92 & 0.34 \\
\hline Vomiting & & & & \\
\hline Yes & $3.63 \%$ & $2.78 \%$ & & \\
\hline No & $96.37 \%$ & $97.22 \%$ & 0.32 & 0.57 \\
\hline Ear pain & & & & \\
\hline Yes & $3.30 \%$ & $1.98 \%$ & 0.91 & 0.34 \\
\hline No & $96.70 \%$ & $98.02 \%$ & 0.91 & 0.34 \\
\hline Ear ooze & & & & \\
\hline Yes & $0.66 \%$ & $0.00 \%$ & 167 & 020 \\
\hline No & $99.34 \%$ & $100.00 \%$ & $1.6 /$ & 0.20 \\
\hline Eye itch & & & & \\
\hline Yes & $6.93 \%$ & $5.16 \%$ & 0.75 & 0.39 \\
\hline No & $93.07 \%$ & $94.84 \%$ & 0.15 & 0.39 \\
\hline Bloodshot eyes & & & & \\
\hline Yes & $4.62 \%$ & $3.97 \%$ & 014 & 071 \\
\hline No & $95.38 \%$ & $96.03 \%$ & 0.14 & 0.71 \\
\hline Eye discharge & & & & \\
\hline Yes & $9.24 \%$ & $5.56 \%$ & 267 & 010 \\
\hline No & $90.76 \%$ & $94.44 \%$ & 2.07 & 0.10 \\
\hline No symptom & & & & \\
\hline Yes & $0.66 \%$ & $0.00 \%$ & 167 & 020 \\
\hline No & $99.34 \%$ & $100.00 \%$ & & \\
\hline
\end{tabular}

3.4. The Program Effect on Medical Care Utilization. Medical care utilization was divided into medical care utilization days and total medical cost. Medical care utilization days were subcategorized into total visit days, prescription days of drugs, and prescription days of antibiotics.
Without control for any covariates, total visit days during the intervention period increased by 0.22 in the untreated group and decreased by 0.6 in the treated group. Drug prescription days increased by 0.33 days in the untreated but decreased by 1.12 days in the treated group. Antibiotics 
TABLE 4: Inclusion and exclusion criteria of diagnosis.

\begin{tabular}{|c|c|c|c|c|}
\hline Classification of diseases & Inclusion criteria & Exclusion criteria & Total episodes & Included episodes \\
\hline $\begin{array}{l}\text { Certain infectious and parasitic diseases } \\
\text { (A00-B99) }\end{array}$ & Including all & & 201 & 201 \\
\hline Neoplasms (C00-D48) & & Excluding all & 0 & 0 \\
\hline $\begin{array}{l}\text { Diseases of the blood and blood-forming } \\
\text { organs and certain disorders involving the } \\
\text { immune mechanism (D50-D89) }\end{array}$ & & Excluding all & 1 & 0 \\
\hline $\begin{array}{l}\text { Endocrine, nutritional, and metabolic } \\
\text { diseases (E00-E90) }\end{array}$ & & Excluding all & 4 & 0 \\
\hline Mental and behavioral disorders (F00-F99) & & Excluding all & 113 & 0 \\
\hline Diseases of the nervous system (G00-G99) & & Excluding all & 58 & 0 \\
\hline Diseases of the eye and adnexa (H00-H59) & & $\begin{array}{l}\text { Excluding myopia, } \\
\text { strabismus, and so forth }\end{array}$ & 112 & 87 \\
\hline $\begin{array}{l}\text { Diseases of the ear and mastoid process } \\
(\mathrm{H} 60-\mathrm{H} 95)\end{array}$ & & $\begin{array}{l}\text { Excluding cholesteatoma } \\
\text { and so forth }\end{array}$ & 269 & 248 \\
\hline Diseases of the circulatory system (I00-I99) & & Excluding all & 0 & 0 \\
\hline Diseases of the respiratory system (J00-J99) & Including all & & 2840 & 2840 \\
\hline Diseases of the digestive system (K00-K93) & & $\begin{array}{l}\text { Excluding dental diseases, } \\
\text { hernia, etc. }\end{array}$ & 275 & 186 \\
\hline $\begin{array}{l}\text { Diseases of the skin and subcutaneous tissue } \\
\text { (L00-L99) }\end{array}$ & & Excluding all & 160 & 0 \\
\hline $\begin{array}{l}\text { Diseases of the musculoskeletal system and } \\
\text { connective tissues (M00-M99) }\end{array}$ & & Excluding all & 12 & 0 \\
\hline $\begin{array}{l}\text { Diseases of the genitourinary system } \\
\text { (N00-N99) }\end{array}$ & Including all & & 15 & 15 \\
\hline $\begin{array}{l}\text { Pregnancy, childbirth, and the puerperium } \\
\text { (O00-O99) }\end{array}$ & & Excluding all & 0 & 0 \\
\hline $\begin{array}{l}\text { Certain conditions originating in the } \\
\text { perinatal period (P00-P96) }\end{array}$ & & Excluding all & 0 & 0 \\
\hline $\begin{array}{l}\text { Congenital malformations, deformations, } \\
\text { and chromosomal abnormalities (Q00-Q99) }\end{array}$ & & Excluding all & 14 & 0 \\
\hline $\begin{array}{l}\text { Symptoms, signs, and abnormal clinical and } \\
\text { laboratory findings (R00-R99) }\end{array}$ & $\begin{array}{l}\text { Including epistaxis, } \\
\text { cough, fever, and abd. } \\
\text { pain }\end{array}$ & $\begin{array}{l}\text { Excluding abnormalities of } \\
\text { gait and mobility, lack of } \\
\text { growth, and so forth }\end{array}$ & 143 & 33 \\
\hline $\begin{array}{l}\text { Injury, poisoning, and other certain } \\
\text { consequences of external causes (S00-T98) }\end{array}$ & & Excluding all & 129 & 0 \\
\hline $\begin{array}{l}\text { External causes of morbidity and mortality } \\
\text { (V01-Y98) }\end{array}$ & & Excluding all & 0 & 0 \\
\hline $\begin{array}{l}\text { Factors influencing health status and contact } \\
\text { with health services (Z00-Z99) }\end{array}$ & & Excluding all & 10 & 0 \\
\hline Codes for special purposes (U00-U99)* & $\begin{array}{c}\text { Including } \\
\text { pattern/syndrome of lung } \\
\text { (肺系) }\end{array}$ & $\begin{array}{l}\text { Excluding fatigue due to } \\
\text { overexertion (勞倦) }\end{array}$ & 24 & 6 \\
\hline Total & & & 4379 & 3615 \\
\hline
\end{tabular}

${ }^{*}$ Including medical care utilization of traditional Korean medicine.

prescription days during the intervention period decreased by 0.04 days in the untreated and also decreased by 0.91 days in the treated group. Medical cost increased by $W 7,863$ in the untreated and decreased by $\$ 8,757$ in the treated group.

In the panel regression, the count data such as visit days, drugs prescription days, and antibiotics prescription days are analyzed by the negative binomial model. First, incidence rate ratios comparing the treated and untreated groups with regard to the medical care utilization days were examined while holding constant the previously discussed covariates. $12 \%$ of significant reduction in total visit days of hospitals were associated with the intervention (incident rate ratio $=$ $0.88, P=0.01$ ), but the reductions of drug prescription days and antibiotics prescription days were not statistically significant.

Second, we compared the medical cost due to common infectious diseases between the treated and untreated groups. The medical cost was log-transformed since it is skewed 
TABLE 5: Characteristics of participants.

\begin{tabular}{|c|c|c|c|}
\hline & & $\begin{array}{c}\text { Treated } \\
(n=227)\end{array}$ & $\begin{array}{c}\text { Untreated } \\
(n=92)\end{array}$ \\
\hline \multicolumn{4}{|c|}{ Dependent variables } \\
\hline \multirow{4}{*}{ Medical care utilization } & Visit days & $6.01 \pm 0.41$ & $5.52 \pm 0.52$ \\
\hline & Total cost (W) & $87,640 \pm 8,938$ & $67,873 \pm 6,936$ \\
\hline & Prescription days & $16.22 \pm 1.13$ & $17.37 \pm 1.89$ \\
\hline & Prescription days of antibiotics & $10.80 \pm 0.91$ & $11.12 \pm 1.24$ \\
\hline \multicolumn{4}{|c|}{ Independent variables } \\
\hline \multicolumn{2}{|c|}{ Age } & $5.48 \pm 0.08$ & $5.62 \pm 0.12$ \\
\hline \multirow{2}{*}{ Sex } & Male & $131(57.71)$ & $50(54.35)$ \\
\hline & Female & $96(42.29)$ & $42(45.65)$ \\
\hline \multirow{2}{*}{ Duration } & Under 1 yr & $63(28.90)$ & $18(21.69)$ \\
\hline & Over $1 \mathrm{yr}$ & $155(71.10)$ & $65(78.31)$ \\
\hline \multirow{2}{*}{ Past history } & Yes & $121(56.81)$ & $47(58.02)$ \\
\hline & No & $92(43.19)$ & $34(41.98)$ \\
\hline \multicolumn{2}{|c|}{ Number of siblings } & $1.96 \pm 0.61$ & $1.98 \pm 0.71$ \\
\hline \multirow{2}{*}{ Main carer* } & Mother & $202(91.82)$ & $69(83.13)$ \\
\hline & etc. & $18(8.18)$ & $14(16.87)$ \\
\hline \multirow{2}{*}{ NHI } & Medicaid & $9(4.04)$ & $3(3.30)$ \\
\hline & National Health Ins. & $214(95.96)$ & $88(96.70)$ \\
\hline \multirow{2}{*}{ Income* } & Under 4,000 & $128(60.38)$ & $34(40.96)$ \\
\hline & Over 4,000 & $84(39.62)$ & $49(59.04)$ \\
\hline \multirow{2}{*}{ Mom's education } & Below high school & $36(16.98)$ & $17(21.25)$ \\
\hline & Over college & $176(83.02)$ & $63(78.75)$ \\
\hline \multirow{2}{*}{ Mom’s Job } & Working mom & $103(47.91)$ & $37(44.58)$ \\
\hline & Household & $112(53.02)$ & $46(55.42)$ \\
\hline
\end{tabular}

${ }^{*} P<0.05$.

with long right tail. The results show that the intervention program had a negative impact on medical cost, but it was not statistically significant (Table 6).

As a result, total visit days were 2.67 in the treated group and 2.79 in the untreated group. The marginal effect of the program was -0.12 .

\section{Conclusions}

It is generally agreed that implementation of comprehensive health care program in child-care centers is important in minimizing common infections and promoting children's health [16-22]. However, documentation of the benefits of such a program has been incomplete. Several leading researches have studied the effect of health intervention program on infections in child-care centers and emphasized the importance of prevention and management for infectious diseases in child-care centers. But some research compared only pre- and post-results without control groups [17, 23], and some just used staff's records or surveys of parents as outcomes [17-22].

Our study tried to overcome these limitations in several ways. First, we performed this study as quasi-experimental design by matching the case group with the control group having similar features like location, ownership, and size. Although the perfect randomization was not possible, the maturation effect, which means changes in characteristics of target population by the passage of time, and extraneous environmental effect could be controlled. Second, we tried to estimate more accurate effect of intervention statistically. The various, observable characteristics of participants were controlled by a multivariate regression model. In addition, time-invariant, unobserved, individual-specific effect that could affect the outcome could be controlled by using a panel model. Third, we used objective data of health insurance claim to measure outcome variables. Analyzing claim data has many advantages, including a lower risk of recall bias and coverage of the whole intervention period into analysis without recall bias, compared to survey. Besides, claim data can provide accurate diagnosis, number of days, and cost due to infections, which makes it possible to screen specific episodes adequate for the study. It is meaningful that this study has overcome some methodological concerns, such as limitation of data supporting the efficacy of the intervention, objective measurements, and analytic techniques, which were mentioned by Huskins [24]. 


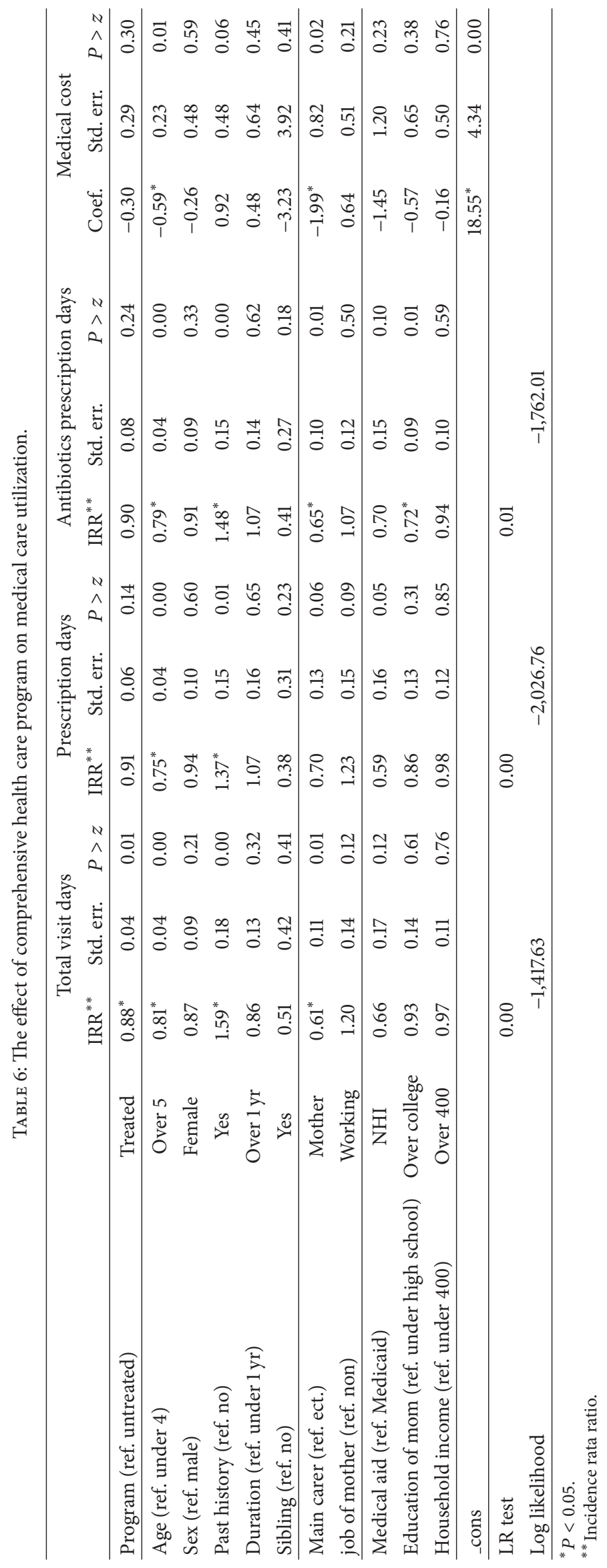


Furthermore, our program tried to take advantages of comprehensive and preventive aspects of traditional medicine and applied it to practice. For example, this program not only provided the health management of children, but also educated teachers and parents about the prevention of common infectious diseases, including health promotion in Korean medicine. So, the intervention encompasses not only primary prevention, but also secondary prevention by providing household polyherbal medicines and conducting medical examination, which permit early detection of diseases and proper reaction.

Empirical results showed that $12 \%$ of significant reduction in total visit days of hospitals were associated with the intervention (incident rate ratio $=0.88, P=0.01$ ). This implies that the treated group visited physicians less, specifically 0.12 times less per person, controlling for observable covariates and unobservable time-invariant variables. This is an improved result compared with Park et al. [12], which evaluated the same intervention based on survey and showed that the total medical care utilization due to infectious diseases decreased, but without statistical significance. On the other hand, drugs prescription days, antibiotics prescription days, and medical cost decreased, but not statistically significant.

In this research, we only focused on measuring the effect of child-care center program on medical care utilization due to infectious diseases. If we just focus on the medical utilization, it would not be surprising that providing doctors onsite would decrease the number of visits to outside medical practitioners. But one should note that most of preventive interventions were performed using Korean traditional herbal medicines according to the Korean traditional medicine theory. In addition, this result was just one aspect of evaluation and other comprehensive effects were also reported by Park et al. [12], which showed the significant decrease in children's absence/lateness days and high parents' satisfaction with this intervention.

Finally, this research shows that comprehensive health care program using traditional medicine decreased medical utilization significantly, which can be a big benefit for those parents who work. Reduced medical care utilization of children results in reduced wage loss for working parents, who should accompany their children in case of medical care utilization. Further cost-effectiveness analysis in terms of social perspectives considering the opportunity costs for guardians to take children to the medical institutions would increase the value of the intervention in this study.

Nevertheless, there are also limitations in this study. First, non-randomly assigned control group could pose a selection bias problem although various efforts were made to overcome this limitation. Second, nonconsenters for using their claim data were excluded in data analysis. We compared the demographic, socioeconomic features and frequency of infection-related symptoms between the consenters and nonconsenters and could not observe any systemic differences. But there is still a possibility that it had an effect on the result. Third, we controlled the time-invariant and unobservable confounding factors by panel model, but the individualspecific time-variant factors still could not be controlled completely.
In spite of limitations, this research suggests that comprehensive health care program using traditional medicine can be effective to manage infections in child-care centers. In future studies, the implementation of sufficient long-term intervention to a larger sample would be helpful to overcome the limitations, as the period of this intervention was relatively short and the number of infants that provide information on medical care utilization was not large.

\section{Conflict of Interests}

The authors declare that there is no conflict of interests regarding the publication of this paper.

\section{References}

[1] J. P. Niffenegger, "Proper handwashing promotes wellness in child care," Journal of Pediatric Health Care, vol. 11, no. 1, pp. 26-31, 1997.

[2] CDC, "Public health considerations of infectious diseases in child day care centers. The child day care infectious disease study group," Journal of Pediatrics, vol. 105, no. 5, pp. 683-701, 2004.

[3] D. M. Bell, D. W. Gleiber, A. A. Mercer et al., "Illness associated with child day care: a study of incidence and cost," The American Journal of Public Health, vol. 79, no. 4, pp. 479-484, 1989.

[4] A. T. Berg, E. D. Shapiro, and L. A. Capobianco, "Group day care and the risk of serious infectious illnesses," The American Journal of Epidemiology, vol. 133, no. 2, pp. 154-163, 1991.

[5] R. Haskins and J. Kotch, "Day care and illness: evidence, costs, and public policy," Pediatrics, vol. 77, no. 6, pp. 951-982, 1986.

[6] F. W. Henderson, P. H. Gilligan, K. Wait, and D. A. Goff, "Nasopharyngeal carriage of antibiotic-resistant pneumococci by children in group day care," Journal of Infectious Diseases, vol. 157, no. 2, pp. 256-263, 1988.

[7] E. R. Wald, N. Guerra, and C. Byers, "Frequency and severity of infections in day care: three-year follow-up," The Journal of Pediatrics, vol. 118, no. 4, pp. 509-514, 1991.

[8] W. Lu, "Minutes on traditional and modern medicine harmonizing symposium," Chinese Journal of Integrative Medicine, vol. 6, no. 1, p. 80, 2000.

[9] W. Hoff, "Traditional health practitioners as primary health care workers," Tropical Doctor, vol. 27, no. 1, pp. 52-55, 1997.

[10] J. G. Jo, Research on the Actual Condition of Korean Medicine Utilization and Herbal Medicine Consumption, Ministry of Health and Welfare, Seoul, Republic of Korea, 2011.

[11] Depatrment of Health and Welfare, Child Care Statistics, 2012.

[12] J. M. Park, M. J. Park, and B. H. Cho, "Development and evaluation of comprehensive health care program for infectious disease management in child care centers by doctor of Korean Medicine," Korean Journal of Health Education and Promotion, vol. 30, no. 1, pp. 65-81, 2013.

[13] A. K. Kim, "The study of Yangsaeng and fatigue in adult men," Journal of Korean Academy of Fundamentals of Nursing, vol. 18, no. 1, pp. 79-86, 2011.

[14] J. H. Min, Y. S. Back, W. C. Jung, and C. H. Jung, "A study on the theory of chimibyeong," Journal of Oriental Medical Classics, vol. 23, no. 1, pp. 257-277, 2010.

[15] J. A. Hausman and W. E. Taylor, "Panel data and unobservable individual effects," Econometrica, vol. 49, no. 6, pp. 1377-1398, 1981. 
[16] H. Carabin, T. W. Öyorkos, J. C. Soto, L. Joseph, P. Payment, and J. Collet, "Effectiveness of a training program in reducing infections in toddlers attending day care centers," Epidemiology, vol. 10, no. 3, pp. 219-227, 1999.

[17] L. R. Krilov, S. R. Barone, F. S. Mandel, T. M. Cusack, D. J. Gaber, and J. R. Rubino, "Impact of an infection control program in a specialized preschool," The American Journal of Infection Control, vol. 24, no. 3, pp. 167-173, 1996.

[18] R. E. Black, A. C. Dykes, K. E. Anderson et al., "Handwashing to prevent diarrhea in day-care centers," American Journal of Epidemiology, vol. 113, no. 4, pp. 445-451, 1981.

[19] A. M. Butz, E. Larson, P. Fosarelli, and R. Yolken, "Occurrence of infectious symptoms in children in day care homes," American Journal of Infection Control, vol. 18, no. 6, pp. 347-353, 1990.

[20] M. Uhari and M. Möttönen, "An open randomized controlled trial of infection prevention in child day-care centers," Pediatric Infectious Disease Journal, vol. 18, no. 8, pp. 672-677, 1999.

[21] J. S. Kim, "Effects of a training program on infection prevention for staff of child daycare centers," Child Health Nursing Research, vol. 13, no. 4, pp. 467-477, 2007.

[22] J. B. Kotch, K. A. Weigle, D. J. Weber et al., "Evaluation of an hygienic intervention in child day-care centers," Pediatrics, vol. 94, no. 6, pp. 991-994, 1994.

[23] Y. Razon, S. Ashkenazi, A. Cohen et al., "Effect of educational intervention on antibiotic prescription practices for upper respiratory infections in children: a multicentre study," Journal of Antimicrobial Chemotherapy, vol. 56, no. 5, pp. 937-940, 2005.

[24] W. C. Huskins, "Transmission and control of infections in outof-home child care," Pediatric Infectious Disease Journal, vol. 19, no. 10, pp. S106-S110, 2000. 


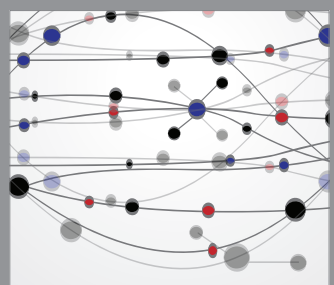

The Scientific World Journal
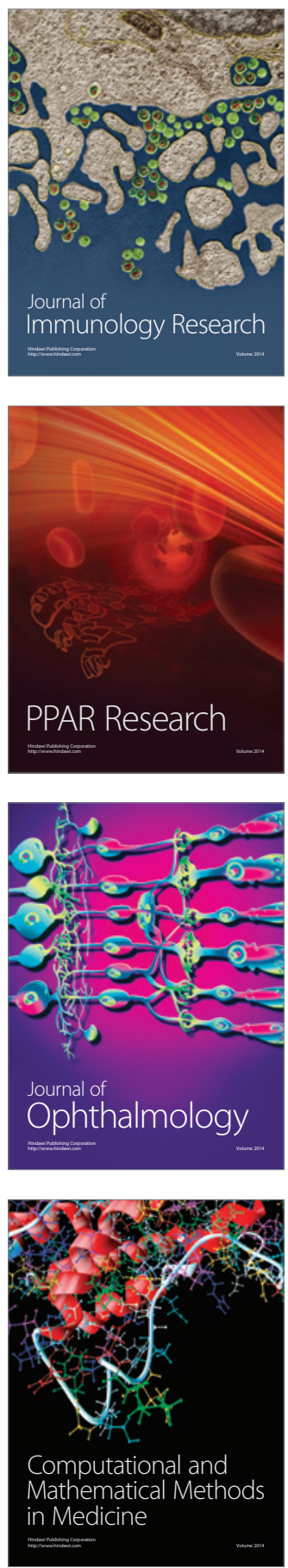

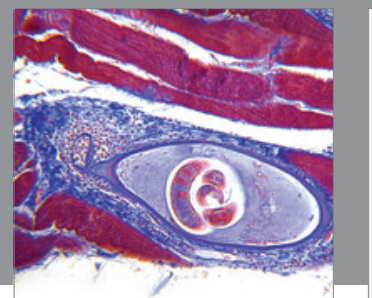

Gastroenterology

Research and Practice
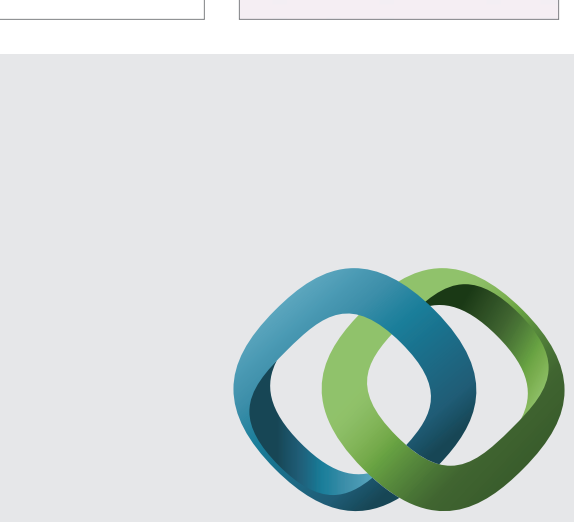

\section{Hindawi}

Submit your manuscripts at

http://www.hindawi.com
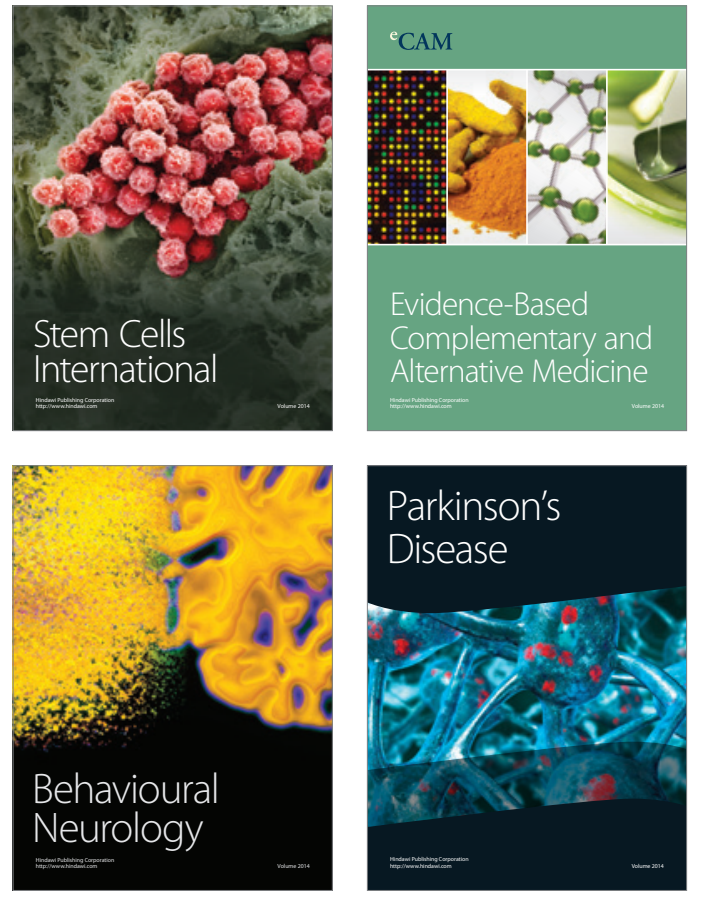
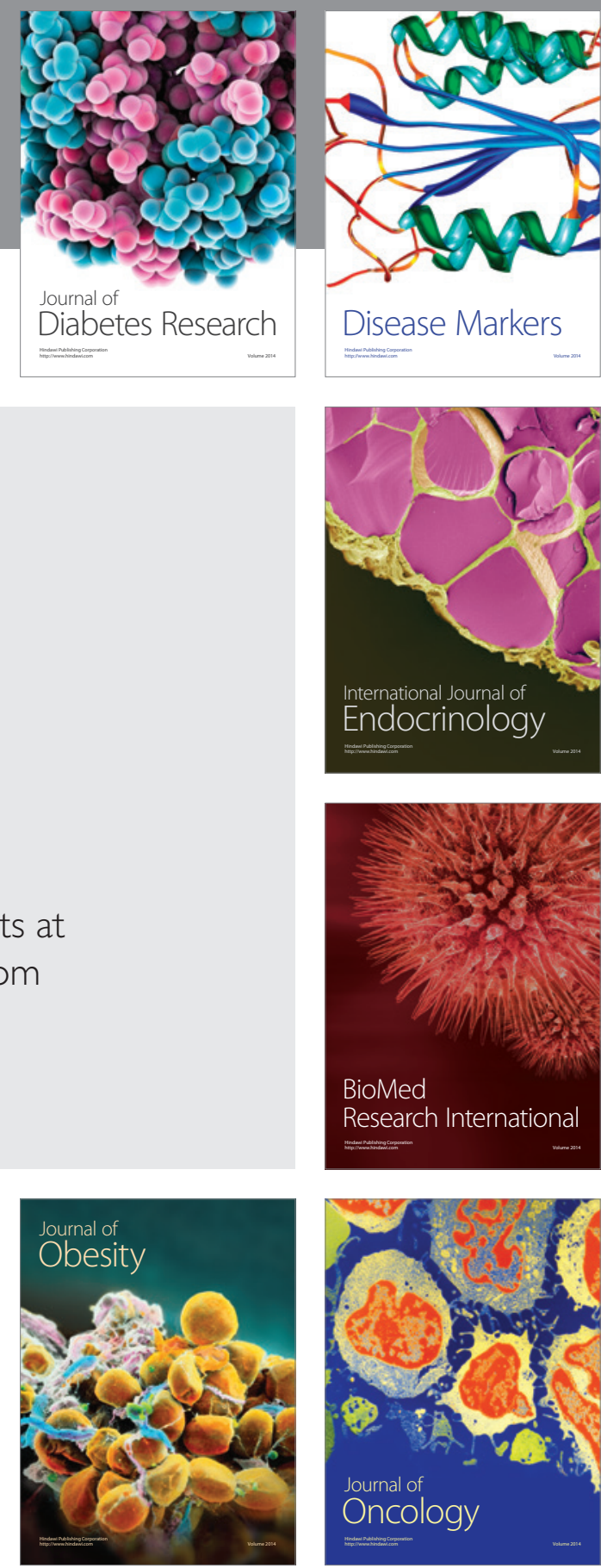

Disease Markers
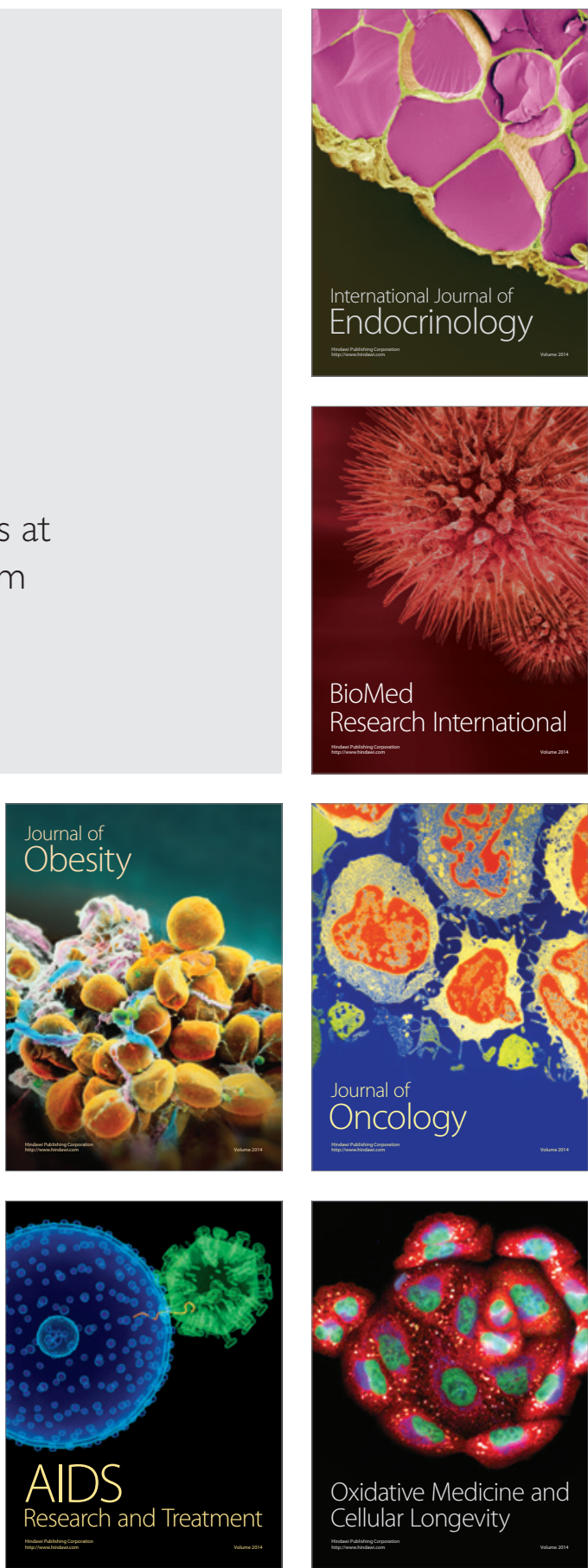